\title{
Relações entre as Características da Madeira e do Carvão Vegetal de duas Espécies da Caatinga
}

\author{
Pedro Nicó de Medeiros Neto ${ }^{1}$, Elisabeth de Oliveira², \\ Juarez Benigno Paes ${ }^{3}$
}

${ }^{1}$ Pós-graduação em Ciências Florestais, Universidade Federal do Espirito Santo - UFES, Jerônimo Monteiro/ES, Brasil ${ }^{2}$ Unidade Acadêmica de Engenharia Florestal - UFCG, Patos/PB, Brasil

${ }^{3}$ Departamento de Ciências Florestais e da Madeira, Universidade Federal do Espírito Santo - UFES, Jerônimo Monteiro/ES, Brasil

\begin{abstract}
RESUMO
A vegetação da Caatinga é explorada para energia, mas existem poucos estudos sobre as relações entre as características da madeira e seu potencial energético. Assim, o objetivo desta pesquisa foi relacionar as características da madeira e do carvão vegetal das espécies catingueira (Poincianella pyramidalis) e pau-d'arco (Handroanthus impetiginosus). Foram abatidas cinco árvores por espécie e retirados toretes de $30 \mathrm{~cm}$ de comprimento a 0 (base), 25, 50, 75 e 100\% da altura comercial da árvore. Esse material foi utilizado para determinação das características da madeira e do carvão vegetal. A catingueira produziu maior rendimento em carvão vegetal que o pau-d'arco; no entanto, a madeira desta espécie apresentou melhores características para fins energéticos. As duas espécies apresentaram relações entre as características anatômicas, físico-químicas e energéticas diferentes. O conhecimento da disparidade entre as relações das características da madeira possibilita o uso mais adequado da mesma para fins energéticos.
\end{abstract}

Palavras-chave: energia, biomassa, catingueira, pau-d'arco.

\section{Relationship between the Characteristics of Wood and Charcoal of two Caatinga Tree Species}

\begin{abstract}
The Caatinga vegetation is explored for energy, but there are few studies on the relationship between of the characteristics of wood and its energy potential. Therefore, this study aimed to relate the characteristics of wood and charcoal of Poincianella pyramidalis and Handroanthus impetiginosus species. To this end, five trees of each species were felled, and parts of $30 \mathrm{~cm}$ in length were removed at 0 (base), 25, 50, 75 and $100 \%$ of the commercial height of the trees. This material was used for determination of the characteristics of wood and charcoal. $P$. pyramidalis produced greater yield of charcoal compared with $H$. impetiginosus; however, the wood of the latter species presented better characteristics for energy purposes. The two species showed different relations between anatomical, physicochemical and energy characteristics. The knowledge about the disparity between the relations of the wood characteristics enables its most adequate use for energy purposes.
\end{abstract}

Keywords: energy, biomass, Poincianella pyramidalis, Handroanthus impetiginosus. 


\section{INTRODUÇÃO}

A vegetação nativa da região semiárida do nordeste brasileiro, a Caatinga, vem sendo explorada e utilizada de forma intensiva e de maneira inadequada, para finalidades energéticas e nas construções rurais (cercas, currais, telhados e pocilgas), contribuindo para a escassez da madeira em vários locais. Evidencia-se a sua importância por ser uma matéria-prima renovável, mais acessível e menos poluente, quando comparada aos combustíveis fósseis.

A Caatinga é o único bioma exclusivamente brasileiro, com uma área de $844.453 \mathrm{~km}^{2}$ (MMA, 2007). Araújo et al. (2007) relatam que a cobertura florestal da região semiárida tem sido reduzida drasticamente, fato ocasionado por falta de manejo adequado e pelo tipo de exploração adotado. Ainda enfatizam que a exploração da vegetação da região é basicamente realizada com finalidade energética.

Paes et al. (2013) destacaram que o uso florestal na região é para forragem e fins medicinais e energéticos, sendo este último o de maior valor econômico. Entretanto, em relação ao conhecimento científico do potencial energético das espécies, são necessários mais estudos.

Uma das principais vantagens ambientais do uso da biomassa com finalidade energética, em comparação aos combustíveis fósseis, é uma diminuição na emissão dos gases que causam o efeito estufa e provocam mudanças climáticas. Desta forma, há a necessidade de pesquisas cientificas com o uso de matérias renováveis, para diversificar as fontes de energia e reduzir a dependência da humanidade de produtos de origem não renovável (Ghilardi et al., 2013; Protásio et al., 2013).

A catingueira (Poincianella pyramidalis Tul. L.P.Queiroz) pertence à família Fabaceae. É uma das espécies de maior ocorrência no semiárido brasileiro (Maia, 2004; Siqueira Filho et al., 2009), sendo utilizada na construção rural e como fonte energética (lenha e carvão). O pau-d’arco [Handroanthus impertiginosus (Mart. ex DC.) Mattos] pertence à família Bignoniaceae (Siqueira Filho et al., 2009) e produz madeira de qualidade, usada como pontes, mourões, construção civil e naval (Maia, 2004).
A descrição anatômica (Burger \& Richter, 1991), a composição química (Sjöström, 1993) e a densidade (Vital, 1984) formam os parâmetros que constituem a base para quaisquer estudos tecnológicos que sejam efetuados na madeira. A densidade é a propriedade física que melhor se relaciona com as características mecânicas do material.

De acordo com Lima et al. (2007), a madeira é constituída por celulose, hemicelulose e lignina componentes primários, responsáveis pela formação da parede celular e pela maioria de suas propriedades - e pelos extrativos e cinzas, os componentes secundários.

A presença de extrativos aumenta a densidade da madeira e ocasiona a produção de um carvão mais denso. O teor de cinzas é importante, pois, com teores elevados, serão necessárias mais limpezas em fornalhas e em outros sistemas em que a madeira é utilizada como fonte de energia, provocando danificação dos equipamentos (Oliveira, 2003).

Segundo Protásio et al. (2012), para avaliar a degradação térmica da madeira na produção do carvão vegetal, o estudo das características químicas e físicas é essencial, e existe a necessidade de pesquisas que realizem relações entre o carvão e o material de origem (madeira).

Ao considerar que os componentes primários da madeira são basicamente constituídos por oxigênio (44\%), hidrogênio (6\%) e carbono (50\%), o fenômeno da carbonização pode ser explicado a partir das mudanças sofridas por esses três componentes (Oliveira, 2003).

Oliveira (2003) e Oliveira et al. (2010) relatam que as propriedades químicas desejáveis do carvão, como teores de carbono fixo e de substâncias voláteis e cinzas, estão associadas ao teor de lignina da madeira e às condições de carbonização, como, temperatura final e taxa de aquecimento, pois maiores temperaturas e taxas de aquecimento reduzem o rendimento em carvão vegetal e favorecem a geração de gases devido à maior degradação térmica dos componentes da madeira.

Pela importância e pela diversidade de usos da madeira, além da carência de informações sobre a vegetação da Caatinga, esta pesquisa teve como objetivo correlacionar as características anatômicas, físico-químicas e energéticas da madeira com os 
rendimentos da carbonização e as características do carvão vegetal de duas espécies florestais de ocorrência no semiárido brasileiro.

\section{MATERIAL E MÉTODOS}

\subsection{Coleta e amostragem das madeiras}

Foram coletadas madeiras de catingueira (Poincianella pyramidalis) e de pau-d'arco (Handroanthus impertiginosus), sendo selecionadas cinco árvores de cada espécie, que apresentavam boa fitossanidade. As madeiras foram coletadas no município de São Mamede, Estado da Paraíba, com localização $06^{\circ} 54^{\prime} 55^{\prime \prime}$ S e $37^{\circ} 05^{\prime} 55^{\prime \prime}$ W, a $265 \mathrm{~m}$ de altitude, distante $300 \mathrm{~km}$ de João Pessoa, capital do Estado.

De cada árvore, foram retirados toretes com 30 cm de comprimento a 0 (base), 25, 50, 75 e 100\% da altura comercial da árvore, considerada até $5,0 \mathrm{~cm}$ de diâmetro. Essas amostras foram identificadas e transportadas para o Laboratório de Tecnologia de Produtos Florestais (LTPF) da Unidade Acadêmica de Engenharia Florestal (UAEF), Universidade Federal de Campina Grande (UFCG), Campus de Patos$\mathrm{PB}$, para a realização das análises físicas, químicas, anatômicas (dimensões de fibras) e energéticas das madeiras, os rendimentos da carbonização e a caracterização do carvão produzido pelas espécies estudadas.

Da porção mediana de cada torete, foi retirado um disco de 2,5 cm de espessura, que foi subdividido em quatro partes, em forma de cunha, passando pela medula. Duas cunhas opostas foram utilizadas para a determinação da massa específica básica e as restantes foram reservadas para possível necessidade de materiais.

\subsection{Caracterizações físicas, químicas e anatômicas das madeiras}

O volume foi medido de acordo com o método do deslocamento de água, descrito pela Norma Brasileira Regulamentadora - NBR 11941, da Associação Brasileira de Normas Técnicas - ABNT (2003). A determinação da densidade básica média da árvore foi considera a média ponderada, tomando-se o volume entre as seções de retirada dos discos como fator de ponderação.

A análise química da madeira foi efetuada em duplicada, ao empregar a fração de serragem, que passou pela peneira de 40 mesh $(0,42 \mathrm{~mm})$ e ficou retida na peneira de 60 mesh $(0,25 \mathrm{~mm})$, conforme as recomendações das normas citadas na Tabela 1.

O teor de lignina insolúvel foi determinado pelo método Klason, modificado de acordo com o procedimento proposto por Gomide \& Demuner (1986), que é comumente empregado para madeiras de folhosas. Do filtrado restante da análise da lignina Klason, foi realizada a leitura em espectrofotômetro, para determinação da lignina solúvel em ácido, conforme Goldschimid (1971).

O teor de lignina total foi obtido pela soma da quantidade de lignina insolúvel ou residual com a de lignina solúvel em ácido. O teor de holocelulose foi obtido por diferença [\% holocelulose $=100$ - (teor de extrativo + teor de lignina + cinzas na madeira)].

A determinação do teor de cinzas ou minerais da madeira foi efetuada segundo a Associação Brasileira Técnica de Celulose e Papel - ABTCP M-11/77 (ABTCP, 1974). O poder calorífico superior foi determinado por meio de calorímetro adiabático, de acordo com a NBR 8633 da ABNT (1983).

A caracterização anatômica das madeiras teve como base as dimensões das fibras (comprimento,

Tabela 1. Normas utilizadas para análise química da madeira de catingueira e pau-d’arco.

Table 1. Standards used for chemical analysis of Poincianella pyramidalis and Handroanthus impertiginosus woods.

\begin{tabular}{ll}
\multicolumn{1}{c}{ Análise Química } & \multicolumn{1}{c|}{ Normas Utilizadas } \\
\hline Amostragem e preparação da madeira para análise & TAPPI T257 cm-85 (TAPPI, 1996a) \\
\hline Preparação da madeira para análise química & TAPPI T264 om-88 (TAPPI, 1996b) \\
\hline Madeira livre de extrativos & ASTM - D1105 (ASTM, 2005b) \\
Solubilidade da madeira em álcool:tolueno & ASTM - D1107 (ASTM, 2005a) \\
\hline Solubilidade da madeira em água & ASTM - D1110 (ASTM, 2005c) \\
\hline
\end{tabular}

TAPPI = Technical Association of the Pulp and Paper Industry; ASTM = American Society for Testing and Materials . 
largura, espessura de parede e diâmetro de lume). Para tanto, foram retiradas amostras do material restante dos discos de cada árvore. As amostras foram tratadas com solução macerante de acordo com o método de Nicholls, descrito por Ramalho (1987).

Do material macerado resultante, foram montadas lâminas e mensuradas as dimensões das fibras. As medições foram realizadas com lâminas preparadas a fresco. Utilizou-se o software Axio Vision 4.0 para fotografar e medir os elementos anatômicos. Em cada amostra, foram medidas 25 fibras com aumento de cinco vezes, para o comprimento, e 25 fibras com aumento de 20 vezes, para o diâmetro do lume e a largura das fibras. A espessura média das paredes das fibras foi obtida como sendo a metade da diferença entre a largura da fibra e o diâmetro do respectivo lume. Essa etapa foi realizada no Laboratório de Celulose e Papel da Universidade Federal de Viçosa - UFV, Viçosa- MG.

\subsection{Carbonização da madeira e análise do carvão vegetal}

As carbonizações foram realizadas em um forno elétrico (mufla), com controle de temperatura. O controle de aquecimento foi manual, seguindo a marcha: $150{ }^{\circ} \mathrm{C}-1 \mathrm{~h} ; 200{ }^{\circ} \mathrm{C}-1 \mathrm{~h} ; 250{ }^{\circ} \mathrm{C}-1,5 \mathrm{~h} ; 350$ ${ }^{\circ} \mathrm{C}-1,5 \mathrm{~h} ; 450{ }^{\circ} \mathrm{C}-0,5 \mathrm{~h}$. Foram carbonizados $320 \mathrm{~g}$ anidra de cavacos, com duas duplicatas por árvore, totalizando dez carbonizações por espécie. Os gases foram conduzidos para um condensador tubular, com recolhimento do líquido pirolenhoso. Após a carbonização, o rendimento gravimétrico em carvão e em condensados foi determinado ao dividir a massa do carvão seco resultante ou do condensado produzido pela massa da madeira seca.

As análises do carvão foram realizadas em duplicatas, com quatro replicações por indivíduo, sendo realizadas análises químicas imediatas, determinação da densidade verdadeira e densidade aparente. A composição química imediata foi realizada conforme NBR 8112 da ABNT (1986), com determinações de matérias voláteis, teor de cinzas e de carbono fixo, em base seca. O rendimento em carbono fixo foi obtido ao multiplicar o teor de carbono fixo pelo rendimento gravimétrico do carvão.
As densidades verdadeira e aparente do carvão foram calculadas de acordo com a ASTM D167, adaptada por Oliveira et al. (1982). O poder calorífico superior foi determinado por meio de um calorímetro adiabático, conforme a NBR 8633 da ABNT (1983).

\subsection{Avaliação dos resultados}

$\mathrm{Na}$ avaliação do experimento, utilizou-se um delineamento inteiramente casualizado, com dois tratamentos (espécies) e cinco repetições (árvores). A avaliação das relações entre as características da madeira e do carvão vegetal foi realizada por meio da análise de correlação de Pearson.

\section{RESULTADOS E DISCUSSÃO}

\subsection{Relações entre as características físicas, químicas, anatômicas e energéticas}

Para realização das relações entre as características da madeira e do carvão vegetal das espécies catingueira e pau-d'arco, utilizaram-se os valores contidos na Tabela 2. Ao considerar o potencial energético das duas espécies, o pau-d’arco se destacou, apesar da menor massa específica básica média, porém com um maior poder calorífico superior, devido ao maior teor de lignina de sua madeira.

Os valores da massa específica básica encontrados para as espécies estudadas foram superiores aos obtidos por Paes et al. (2013), para outras espécies de ocorrência na Caatinga, como jurema-preta (Mimosa tenuiflora), de 929,47 kg.m ${ }^{-3}$; jurema-vermelha (Mimosa arenosa), de 813,22 kg.m $\mathrm{m}^{-3}$; angicovermelho (Anadenanthera colubrina var. cebil), de $780 \mathrm{~kg} \cdot \mathrm{m}^{-3}$. Almeida (2010), ao avaliar as madeiras de cumaru (Amburana cearensis) e jurema-branca (Piptadenia stipulacea), de ocorrência no mesmo bioma, encontrou valores médios de 1.001,93 kg.m ${ }^{-3}$ e $631,81 \mathrm{~kg} \cdot \mathrm{m}^{-3}$, respectivamente.

Santos et al. (2013), ao analisarem oito espécies da Caatinga, encontraram valores de massa específica básica que variaram de $970 \mathrm{~kg} \cdot \mathrm{m}^{-3}$, para o mororó (Bauhinia cheilantha), a $290 \mathrm{~kg} \cdot \mathrm{m}^{-3}$, para a imburana (Commiphora leptophloeos). Para a catingueira, 
Tabela 2. Valores médios das características físico-químicas, anatômicas e energéticas das espécies catingueira e pau-d'arco.

Table 2. Average values of anatomical, physicochemical and energy characteristics of Poincianella pyramidalis and Handroanthus impertiginosus species.

\begin{tabular}{|c|c|c|c|c|c|c|c|c|c|}
\hline \multirow[b]{2}{*}{ Espécies } & \multicolumn{9}{|c|}{ Características Físico-químicas da Madeira } \\
\hline & \multicolumn{2}{|c|}{ MEB $\left(\mathrm{kg} \cdot \mathrm{m}^{-3}\right)$} & CIZM (\%) & \multicolumn{2}{|c|}{ EXT TOT (\%) } & LIG TOT (\%) & \multicolumn{2}{|c|}{ HOL (\%) } & $\begin{array}{c}\text { PCSM } \\
\left(\mathrm{kcal}^{\left.-k^{-1}\right)}\right.\end{array}$ \\
\hline Catingueira & \multicolumn{2}{|c|}{1052,46} & 3,69 & \multicolumn{2}{|c|}{11,81} & 24,64 & \multicolumn{2}{|c|}{59,86} & 4413,50 \\
\hline Pau-d'arco & \multicolumn{2}{|c|}{997,75} & 0,87 & \multicolumn{2}{|c|}{6,88} & 28,40 & \multicolumn{2}{|c|}{63,85} & 4806,30 \\
\hline \multirow[b]{2}{*}{ Espécies } & \multicolumn{9}{|c|}{ Características Físico-químicas do Carvão vegetal } \\
\hline & RG (\%) & RLC (\%) & $\begin{array}{c}\text { MEA } \\
\left(\mathrm{kg} \cdot \mathrm{m}^{-3}\right)\end{array}$ & $\begin{array}{c}\text { MEV } \\
\left(\mathrm{kg} \cdot \mathrm{m}^{-3}\right)\end{array}$ & MV (\%) & $\begin{array}{c}\text { CIZC } \\
(\%)\end{array}$ & CF (\%) & RCF (\%) & $\begin{array}{c}\text { PCSC } \\
\left(\mathrm{kcal}^{\left.-k^{-1}\right)}\right)\end{array}$ \\
\hline Catingueira & 43,03 & 39,06 & 600 & 1260 & 34,15 & 5,27 & 60,58 & 26,04 & 6247,80 \\
\hline Pau-d'arco & 37,90 & 42,37 & 500 & 1200 & 30,36 & 1,96 & 67,67 & 25,65 & 6977,40 \\
\hline
\end{tabular}

\begin{tabular}{lcccc}
\multirow{2}{*}{ Espécies } & \multicolumn{4}{c}{ Características das Fibras da Madeira } \\
\cline { 2 - 5 } & COMPF $(\mathbf{m m})$ & LARGF $(\mathbf{m m})$ & DIALF $(\mathbf{m m})$ & ESPF $(\mathbf{m m})$ \\
Catingueira & 0,83 & 14,56 & 2,78 & 5,89 \\
Pau-d'arco & 0,87 & 14,81 & 2,90 & 5,95 \\
\hline
\end{tabular}

$\mathrm{MEB}=$ massa específica básica; CIZM = cinzas da madeira; EXT TOT = extrativos totais; $\mathrm{LIG}$ TOT = lignina total; HOL = holocelulose; PCSM = poder calorífico superior da madeira; $\mathrm{RG}=$ rendimento gravimétrico; $\mathrm{RLC}=$ rendimento em líquido condensado; $\mathrm{MEA}=$ massa específica aparente; $\mathrm{MEV}=$ massa específica verdadeira; $\mathrm{MV}=$ matérias voláteis; $\mathrm{CIZ}=$ cinzas do carvão; $\mathrm{CF}=$ carbono fixo; $\mathrm{RCF}=$ rendimento em carbono fixo; PCSC = poder calorífico superior do carvão.

os autores obtiveram valor médio de $800 \mathrm{~kg} \cdot \mathrm{m}^{-3}$, sendo este valor inferior ao obtido nesta pesquisa. A diferença pode estar relacionada com a idade das plantas utilizadas.

Costa et al. (2014), ao avaliarem a madeira de cinco espécies de ocorrência no cerrado, encontraram teor de lignina variando entre 19,88 e 26,87\%, valores próximos aos encontrados neste trabalho.

Apesar do maior teor de lignina na madeira, o pau-d'arco apresentou menor rendimento em carvão vegetal. Este fato pode estar associado à qualidade da lignina, cuja relação siringil/guaiacil (S/G) deve ser menor na espécie catingueira. Menor relação $S / G$ favorece a produção de carvão vegetal, uma vez que a lignina apresentará uma estrutura mais condensada e de maior estabilidade térmica. Este resultado também foi observado por Costa et al. (2014), que trabalharam com espécies do cerrado mineiro.

Além disso, em decorrência de a lignina possuir o maior teor de carbono entre os componentes químicos da madeira, pode-se afetar diretamente e maximizar o teor de carbono fixo (Protásio et al., 2012; Reis et al., 2012).

O teor de carbono fixo do carvão vegetal da madeira do pau-d'arco foi maior que o da catingueira, devido ao maior teor de lignina na sua madeira. Esses valores obtidos para o pau-d’arco são essenciais para gerar uma maior quantidade de energia durante o processo de combustão do carvão vegetal, fato que foi observado pelo maior valor do poder calorífico superior do carvão para essa espécie.

Em relação ao teor de cinzas do carvão, a espécie catingueira exibiu um teor de 5,27\%. Ao avaliarem três espécies de ocorrência na Caatinga, Paes et al. (2013) obtiveram valores inferiores a 2,10\%. Uma maior quantidade de cinzas pode resultar na danificação dos equipamentos, além da necessidade de limpezas mais frequentes nos sistemas que utilizam a madeira como fonte energética (Pereira et al., 2013).

O rendimento gravimétrico em carvão vegetal de ambas as espécies foram superiores ao encontrado por Costa et al. (2014), ao estudarem a produção em carvão de cinco espécies florestais do cerrado, com dados expostos em intervalo de 30,88 a 34,39\%. Em relação ao rendimento em carbono fixo, a diferença entre as madeiras variou de 24,53 a $26,56 \%$, resultados semelhantes aos obtidos para as espécies pau-d'arco e catingueira.

O pau-d'arco exibiu valores de poder calorífico da madeira e do carvão superiores aos da espécie 
catingueira. Segundo Santos et al. (2011), esta característica é importante por expressar a quantidade de calor desprendido quando da sua combustão completa da madeira, ao fornecer, desta forma, a capacidade energética de uma determinada espécie. Note-se que tal capacidade é influenciada principalmente pela composição química da madeira, particularmente pelos teores de extrativos e lignina, fato observado pelo maior valor do poder calorífico superior para esta espécie. Santos et al. (2013) obtiveram valores de $4.442 \mathrm{kcal} . \mathrm{Kg}^{-1}$ para a madeira de catingueira, resultado semelhante ao encontrado neste trabalho.

Ao comparar o valor do poder calorífico da madeira de pau-d'arco com o obtido para a madeira de Mimosa tenuiflora, que foi de $4.501,59 \mathrm{kcal}$. $\mathrm{Kg}^{-1}$ (Paes et al., 2013) - a qual é a espécie mais empregada como fonte energética na região da Caatinga -, constata-se que o pau-d'arco possui elevado potencial energético.

A massa específica aparente do carvão de $600 \mathrm{~kg} \cdot \mathrm{cm}^{-3}$ da espécie catingueira foi maior que a encontrada por Costa et al. (2014) para cinco madeiras provenientes do bioma Cerrado, que exibiram resultados no intervalo de 255 a $475 \mathrm{~kg} . \mathrm{m}^{-3}$. Os autores observaram que a espécie de maior massa específica básica também apresentou a maior massa específica aparente do carvão superior, fato observado neste trabalho.

Para as características anatômicas, as espécies cumaru e jurema-branca, pesquisadas por Almeida (2010), tiveram valor de espessura de parede de fibra de 4,52 e 4,54 $\mathrm{mm}$, respectivamente, sendo estes inferiores aos obtidos para as espécies estudadas. No entanto, para o comprimento de fibra, a madeira de cumaru obteve $0,97 \mathrm{~mm}$ e a de jurema branca, $0,78 \mathrm{~mm}$, valores estes superiores (cumaru) e inferiores (jurema branca) aos obtidos para as espécies em estudo.

Paes et al. (2013), ao avaliaram as características das fibras da madeira de angico-vermelho, juremapreta e jurema-vermelha, espécies de ocorrência na Caatinga, observaram que as mesmas tiveram valores de comprimento de fibra e espessura de parede de fibra inferiores aos exibidos para as espécies estudadas. No entanto, os valores de largura da fibra e diâmetro do lume da fibra das espécies pesquisadas por Paes et al. (2013) foram superiores aos obtidos nesta pesquisa.

Observa-se, na Tabela 3, a existência de relações positivas e significativas entre: teor de extrativos totais e rendimento gravimétrico; espessura de fibras e largura de fibras, e rendimento gravimétrico e rendimento em carbono fixo. Relações negativas e significativas entre: teor de holocelulose e teor de extrativos totais; poder calorífico superior da madeira e espessura de fibras; poder calorífico superior da madeira e largura de fibras; teor de holocelulose e rendimento em carbono fixo; densidade verdadeira do carvão e rendimento gravimétrico, e densidade verdadeira do carvão e rendimento em carbono fixo.

Relação negativa entre o teor de extrativos e de holocelulose também foi verificada por Oliveira (1988) para a madeira de Eucalyptus grandis.

Tabela 3. Relações entre variáveis para a madeira de catingueira.

Table 3. Relations among variables for Poincianella pyramidalis wood.

\begin{tabular}{|c|c|c|c|c|c|c|c|c|c|}
\hline Variável & Th & Text & Tl & $\mathbf{R g}$ & Pcsm & Espf & Largf & Rcf & MEv \\
\hline $\mathrm{TH}$ & 1,00 & $-0,91^{*}$ & $-0,85$ & $-0,84$ & 0,55 & $-0,34$ & $-0,38$ & $-0,91^{*}$ & 0,79 \\
\hline TEXT & & 1,00 & 0,55 & $0,95^{\star}$ & $-0,48$ & 0,14 & 0,19 & $-0,48$ & $-0,85$ \\
\hline TL & & & 1,00 & 0,46 & $-0,47$ & 0,49 & 0,51 & 0,73 & $-0,49$ \\
\hline RG & & & & 1,00 & $-0,68$ & 0,34 & 0,38 & $0,89^{*}$ & $-0,96^{*}$ \\
\hline PCSM & & & & & 1,00 & $-0,91^{\star}$ & $-0,92^{*}$ & $-0,80$ & 0,85 \\
\hline ESPF & & & & & & 1,00 & $0,98^{* *}$ & 0,58 & $-0,57$ \\
\hline LARGF & & & & & & & 1,00 & 0,65 & $-0,61$ \\
\hline RCF & & & & & & & & 1,00 & $-0,94^{\star}$ \\
\hline MEV & & & & & & & & & 1,00 \\
\hline
\end{tabular}

$\mathrm{TH}=$ teor de holocelulose; $\mathrm{TEXT}=$ teor de extrativos; $\mathrm{TL}=$ teor de lignina total; $\mathrm{RG}=$ rendimento gravimétrico; $\mathrm{PCSM}=$ poder calorífico superior da madeira; $\mathrm{RCF}=$ rendimento em carbono fixo; $\mathrm{MEV}=$ massa específica verdadeira do carvão; ${ }^{*}$ significativo pelo teste de $t(0,01<\mathrm{p} \leq 0,05)$; ${ }^{* *}$ significativo pelo teste de $\mathrm{t}(\mathrm{p} \leq 0,01)$. 
No entanto, Vale et al. (2010) encontraram uma correlação positiva entre estas variáveis, enfatizando que esses autores analisaram, de forma conjunta, o efeito de cinco espécies diferentes do Cerrado nas características avaliadas.

A relação entre o rendimento gravimétrico e o teor de extrativos totais teve um coeficiente de correlação positivo de 0,95. Observações semelhantes foram obtidas por Oliveira (1988), ao estudar a espécie Eucalyptus grandis. Santos et al. (2011) encontraram correlação positiva de 0,78 entre estas mesmas características ao avaliar clones de Eucalyptus com sete anos de idade e destacaram que alguns constituintes químicos dos extrativos promovem uma maior estabilidade à degradação térmica da madeira e proporcionam aumento no rendimento em carvão vegetal.

Reis et al. (2012) exibiram uma correlação positiva $(0,77)$ entre o rendimento em carvão vegetal e o rendimento em carbono fixo para madeira clonal de Eucalyptus urophylla, com aproximadamente sete anos de idade; tal resultado é semelhante ao encontrado neste trabalho para a espécie catingueira.

Nota-se ainda uma correlação negativa $(-0,84)$ entre o rendimento gravimétrico e o teor de holocelulose. Isto provavelmente ocorreu em virtude de estes componentes químicos serem completamente degradados em temperaturas superiores a $400{ }^{\circ} \mathrm{C}$ e, ao ser utilizado neste trabalho um aquecimento de $450{ }^{\circ} \mathrm{C}$, estes constituintes contribuem pouco para formação do carvão vegetal. Pereira et al. (2013) exibiram correlações negativas para celulose $(-0,32)$ e hemiceluloses $(-0,20)$, ao avaliaram clones de Eucalyptus spp. com aproximadamente 7, 5 anos de idade.

Observa-se, na Tabela 4, a ocorrência de relações positivas e significativas entre teor de lignina e poder calorífico superior da madeira, e teor de holocelulose e comprimento de fibras; também, correlações negativas e significativas, entre: teor de holocelulose $\times$ teor de lignina total; teor de holocelulose $\times$ poder calorífico superior da madeira; massa específica básica da madeira $\times$ diâmetro do lume da fibra; massa específica básica da madeira $\times$ largura de fibras; comprimento de fibras $\times$ rendimento gravimétrico.

Verifica-se, na Tabela 4, uma correlação positiva e não significativa $(0,52)$ entre a massa específica básica da madeira e o teor de lignina. Observações similares foram obtidas por Brito \& Barrichelo (1977), ao estudarem dez espécies de eucalipto com diferentes idades, a uma temperatura máxima de $500{ }^{\circ} \mathrm{C}$ e ciclo total de carbonização de 2,5 horas; também por Protásio et al. (2012), ao avaliarem clones de Eucalyptus sp. com idades que variaram entre 3,8 e 5,7 anos de idade.

Vital et al. (1994) encontraram uma correlação negativa entre essas variáveis para 25 progênies da espécie Eucalyptus camaldulensis com 33 meses de idade, ao empregarem um tempo de carbonização de seis horas e temperatura máxima de $450{ }^{\circ} \mathrm{C}$, durante duas horas.

Observa-se, ainda, uma relação negativa e não significativa $(-0,63)$ entre a massa específica da madeira e o teor de holocelulose, ou seja, espécies de

Tabela 4. Relações entre as variáveis para a madeira pau-d'arco.

Table 4. Relations among variables for Handroanthus impetiginosus wood.

\begin{tabular}{ccccccccccc} 
Variável & MEB & HOL & TL & PCSM & DIALF & LARGF & COMPF & MEV & RG \\
MEB & 1,00 & $-0,63$ & 0,52 & 0,58 & $-0,96^{*}$ & $-0,94^{*}$ & $-0,56$ & 0,32 & 0,55 \\
HOL & & 1,00 & $-0,97^{* *}$ & $-0,97^{* *}$ & 0,56 & 0,49 & $0,90^{*}$ & $-0,29$ & $-0,28$ \\
TL & & & 1,00 & $0,99^{* *}$ & $-0,45$ & $-0,36$ & $-0,82$ & 0,12 & 0,08 \\
PCSM & & & & 1,00 & $-0,55$ & $-0,38$ & $-0,88^{*}$ & 0,24 & 0,21 \\
DIALF & & & & 1,00 & 0,84 & 0,59 & $-0,48$ & $-0,68$ \\
LARGF & & & & & & 1,00 & 0,34 & $-0,18$ & $-0,44$ \\
COMPF & & & & & & & 1,00 & $-0,65$ & $-0,59$ \\
MEV & & & & & & & & & 1,00 & $-0,94^{*}$ \\
RG & & & & & & & & & & \\
\hline
\end{tabular}

$\mathrm{MEB}=$ massa específica básica; $\mathrm{HOL}=$ teor de holocelulose $\mathrm{TL}=$ teor de lignina total; $\mathrm{PCSM}=$ poder calorífico superior da madeira; DIAF = diâmetro do lume da fibra; LARGF = largura de fibra; $\mathrm{COMPF}=$ comprimento de fibra; $\mathrm{MEV}=$ massa específica verdadeira do carvão; RG = rendimento gravimétrico; ${ }^{*}$ significativo pelo teste de $\mathrm{t}(0,01<\mathrm{p} \leq 0,05)$; ${ }^{* *}$ significativo pelo teste de $\mathrm{t}(\mathrm{p} \leq 0,01)$. 
madeiras com maiores massas específicas apresentam menores teores de polissacarídeos. Vale et al. (2010) e Protásio et al. (2012) obtiveram resultados similares.

A relação entre a massa específica básica e o rendimento gravimétrico foi positiva e não significativa $(0,55)$, indicando que amostras de maior massa específica produzem maior rendimento em carvão. Observações semelhantes foram relatadas por Vital et al. (1994) e Vale et al. (2010). Segundo Santos et al. (2011), 60\% da massa da madeira é degradada durante o processo de carbonização para produção de carvão vegetal e, consequentemente, quando maior a massa específica do material lenhoso, maior a massa de carvão por volume, o que ocasiona um produto com superior resistência mecânica.

Observa-se uma relação negativa $(-0,97)$ entre o teor de lignina e o de holocelulose. Resultados similares foram descritos por Oliveira (1988), Vital et al. (1994), Vale et al. (2010) e Protásio et al. (2012).

Houve uma baixa relação $(0,08)$ entre o rendimento gravimétrico e o teor de lignina para a espécie pau-d’arco. Pereira et al. (2013) destacam que a madeira mais lignificada proporcionará uma maior produção em carvão vegetal e elevado poder calorífico, em virtude da degradação mais rápida dos componentes químicos ricos em oxigênio (celulose e hemiceluloses). No entanto, esse fato não ocorreu com esta espécie florestal, pois, provavelmente, outros componentes, como os extrativos, podem estar interferindo no rendimento em carvão vegetal.

Nota-se uma relação negativa entre massa específica básica da madeira e a largura e o diâmetro do lume da fibra. Oliveira (1988) encontrou resultado semelhante para a espécie Eucalyptus grandis.

\section{CONCLUSÕES}

O rendimento em carvão vegetal foi maior para a catingueira, uma vez que a madeira desta espécie possui maior massa específica básica que a madeira de pau-d'arco.

As duas espécies estudadas tiveram relações entre as características anatômicas, físico-químicas e energéticas diferentes, tendo a madeira de paud'arco apresentado melhores características para fins energéticos.
O conhecimento das inter-relações entre as características da madeira possibilita o uso adequado do material, ao se verificar o efeito da influência entre as variáveis analisadas na qualidade do carvão produzido.

A disparidade das relações expostas para ambas as espécies ocorreu principalmente por causa das mesmas pertencerem a famílias botânicas distintas e, também, em virtude de os indivíduos terem sido coletados de povoamentos florestais inequiâneos.

\section{AGRADECIMENTOS}

À Coordenação de Aperfeiçoamento de Pessoal de Nível Superior - CAPES, pelo apoio financeiro ao primeiro autor.

\section{STATUS DA SUBMISSÃO}

Recebido: 11 jul., 2013

Aceito: 08 ago., 2014

Publicado: 21 nov., 2014

\section{AUTOR(ES) PARA CORRESPONDÊNCIA}

\section{Pedro Nicó de Medeiros Neto}

Pós-graduação em Ciências Florestais, Universidade Federal do Espirito Santo - UFES, CEP 29550-000, Jerônimo Monteiro, ES, Brasil e-mail: pedroflorestal@gmail.com

\section{REFERÊNCIAS}

Associação Brasileira de Normas Técnicas - ABNT. NBR 8112: carvão vegetal: análise imediata: método de ensaio. Rio de Janeiro: ABNT; 1986.

Associação Brasileira de Normas Técnicas - ABNT. NBR 8633: carvão vegetal: determinação do poder calorífico: método de ensaio. Rio de Janeiro: ABNT; 1983.

Associação Brasileira de Normas Técnicas - ABNT. NBR 11941: madeira: determinação da densidade básica. Rio de Janeiro: ABNT; 2003.

Associação Brasileira Técnica de Celulose e Papel ABTCP. Normas Técnicas ABCTP. São Paulo: ABTCP; 1974.

Almeida AMC. Avaliação anatômica, físico-química e energética da madeira das espécies Piptadenia stipulacea (Benth.) Ducke e Amburana cearensis (Allemao) A. C. Smith de ocorrência no semiárido nordestino 
brasileiro [dissertação]. Campina Grande: Universidade Federal de Campina Grande; 2010.

American Society for Testing and Materials - ASTM. ASTM D1107: standard test method for ethanol-toluene solubility of wood. Philadelphia: ASTM; 2005a. Book of Standards v. 04.10.

American Society for Testing and Materials - ASTM. ASTM D1105: standard test method for preparation of extractive-free wood. Philadelphia: ASTM; 2005b. Book of Standards v. 04.10.

American Society for Testing and Materials - ASTM. ASTM D1110: standard test methods for water solubility of wood. Philadelphia: ASTM; 2005c. Book of Standards v. 04.10 .

Araújo LVC, Manoel CSP, Paes JB. Características dendrométricas e densidade básica da jurema-preta (Mimosa tenuiflora (Willd.) Poir.) de duas regiões do Estado da Paraíba. Caatinga 2007; 20(1): 89-96.

Brito JO, Barrichelo LEG. Correlação entre as características físicas e químicas da madeira e a produção de carvão: I. densidade e teor de lignina na madeira de eucalipto. IPEF 1977; 14: 9-20.

Burger LL, Richter HG. Anatomia da madeira. São Paulo: Nobel; 1991.

Costa TG, Bianchi ML, Protásio TP, Trugilho PF, Pereira AJ. Qualidade da madeira de cinco espécies de ocorrência no cerrado para produção de carvão vegetal. Cerne 2014; 20(1): 37-46. http://dx.doi.org/10.1590/ S0104-77602014000100005.

Ghilardi A, Mwampamba T, Dutt G. What role will charcoal play in the coming decades? Insights from up-to-date findings and reviews. Energy for Sustainable Development 2013; 17(2): 73-74. http://dx.doi. org/10.1016/j.esd.2013.02.007.

Goldschimid O. Ultraviolet spectra. In: Sarkanen KV, Ludwwig $\mathrm{CH}$, editor. Lignins: occurrence, formation, structure and reactions. New York: John Wiley; 1971. p. 241-266.

Gomide JL, Demuner BJ. Determinação do teor de lignina em material lenhoso: método Klason modificado. O Papel 1986; 47(8): 36-38.

Lima SR, Oliveira GS, Morais SAL, Nascimento EA, Chang R. Estudo dos constituintes macromoleculares, extrativos voláteis e compostos fenólicos da madeira de candeia - Moquinia polymorpha (Less.) DC. Ciência Florestal 2007; 17(2): 145-155.

Maia GN. Caatinga: árvores e arbustos e suas utilidades. São Paulo: D\&Z Computação; 2004.

Ministério do Meio Ambiente - MMA. Mapa de cobertura vegetal dos Biomas brasileiros. Brasília: MMA; 2007.
Oliveira AC, Carneiro ACO, Vital BR, Almeida W, Pereira BLC, Cardoso MT. Parâmetros de qualidade da madeira e do carvão vegetal de Eucalyptus pellita F. Muell. Scientia Forestalis 2010; 38(87): 431-439.

Oliveira E. Características anatômicas, químicas e térmicas da madeira de três espécies de maior ocorrência no semiárido nordestino [tese]. Viçosa: Universidade Federal de Viçosa; 2003.

Oliveira E. Correlações entre parâmetros de qualidade da madeira e do carvão de Eucalyptus grandis (W. Hill exMaiden) [dissertação]. Viçosa: Universidade Federal de Viçosa; 1988.

Oliveira JB, Vivacqua Filho A, Gomes PA. Produção de carvão vegetal: aspectos técnicos. In: Penedo WR, editor. Produção e utilização de carvão vegetal. Belo Horizonte: CETEC; 1982. p. 60-73.

Paes JB, Lima CR, Oliveira E, Medeiros Neto PN. Características físico-química, energética e dimensões das fibras de três espécies florestais do semiárido brasileiro. Floresta e Ambiência 2013; 20(4): 550-555.

Pereira BLC, Carneiro ACO, Carvalho AMML, Colodette JL, Oliveira AC, Fontes MPF. Influenceof chemical composition of Eucalyptus wood on gravimetric yield and charcoal properties. BioResources 2013; 8(3): 4574-4592. http://dx.doi.org/10.15376/ biores.8.3.4574-4592.

Protásio TP, Guimarães Junior LBM, Tonoli GHD, Trugilho PF. Técnicas multivariadas aplicadas à avaliação de resíduos lignocelulósicos para a produção de bioenergia. Ciência Florestal 2013; 23(4): 771-781.

Protásio TP, Trugilho PF, Neves TA, Vieira CMM. Análise de correlação canônica entre características da madeira e do carvão vegetal de Eucalyptus. Scientia Forestalis 2012; 40(95): 317-326.

Ramalho RS. O uso de macerado no estudo anatômico de madeiras. Viçosa: UFV; 1987.

Reis AA, Protásio TP, Melo ICNA, Trugilho PF, Carneiro ACO. Composição da madeira e do carvão vegetal de Eucalyptus urophylla em diferentes locais de plantio. Pesquisa Florestal Brasileira 2012; 32(71): 277 290. http://dx.doi.org/10.4336/2012.pfb.32.71.277.

Santos RC, Carneiro ACO, Castro AFM, Castro RVO, Bianche JJ, Souza MM, et al. Correlações entre os parâmetros de qualidade da madeira e do carvão vegetal de clones de eucalipto. Scientia Forestalis 2011; 39(90): 221-230.

Santos RC, Carneiro ACO, Pimenta AS, Castro RVO, Marinho IV, Trugilho PF, et al. Potencial energético da madeira de espécies oriundas de plano de manejo florestal no Estado do Rio Grande do Norte. Ciência Florestal 2013; 23(2): 491-502. 
Siqueira Filho JA, Santos APB, Nascimento MFS, Espírito Santo FS. Guia de campo de árvores da Caatinga. Petrolina: Franciscana; 2009.

Sjöström E. Wood chemistry: fundamentals and applications. 2nd ed. New York: Mc-Graw Academic Press; 1993.

Technical Association of the Pulp and Paper Industry TAPPI. TAPPI test methods T257 cm-85: sampling and preparing wood for analysis. Atlanta: TAPPI Technology Park; 1996a.

Technical Association of the Pulp and Paper Industry TAPPI. TAPPI test methods T264 om-88: preparation of wood for chemical analysis. Atlanta: TAPPI Technology Park; 1996b.

Vale AT, Dias IS, Santana MAE. Relações entre propriedades químicas, físicas e energéticas da madeira de cinco espécies de Cerrado. Ciência Florestal 2010; 20(1): 137-145.

Vital BR, Almeida J, Valente OF, Pires IE. Características de crescimento das árvores e de qualidade da madeira de Eucalyptus camaldulensis para a produção de carvão. IPEF 1994; 47: 22-28.

Vital BR. Métodos de determinação da densidade da madeira. Viçosa: SIF; 1984. Boletim Técnico n. 1. 